\title{
Parasitóides (Hymenoptera: Braconidae) de Anastrepha Schiner (Diptera: Tephritidae) no estado do Acre
}

\author{
Marcílio José THOMAZINI1 ${ }^{1}$, Elizângela Sampaio de ALBUQUERQUE2 2 \\ RESUMO \\ Este trabalho relata a primeira ocorrência de parasitóides em moscas-das-frutas do gênero Anastrepha Schiner no estado do Acre. \\ No município de Bujari foram encontrados os braconídeos Opius bellus Gahan (72,5\%), Doryctobracon areolatus (Szépligeti) \\ $(26,8 \%)$ e Utetes anastrephae (Viereck) $(0,7 \%)$ associados a A. obliqua (Macquart) em frutos de taperebá (Spondias mombin \\ L.), com parasitismo de 29,5\%. No município de Rio Branco, em frutos de goiaba (Psidium guajava L.), ocorreu somente $D$. \\ areolatus em $A$. obliqua com parasitismo de $2,7 \%$.
}

PALAVRAS-CHAVE: Moscas-das-frutas, Parasitismo, Taperebá, Goiaba, Amazônia Ocidental

\section{Parasitoids (Hymenoptera: Braconidae) of Anastrepha Schiner (Diptera: Tephritidae) in the state of Acre, Brazil}

\section{ABSTRACT}

This paper records the first parasitoids occurrence on Anastrepha Schiner fruit flies in the state of Acre, Brazil. In the Bujari County there occurred the braconids Opius bellus Gahan (72.5\%), Doryctobracon areolatus (Szépligeti) (26.8\%) e Utetes anastrephae (Viereck) (0.7\%) associated with A. obliqua (Macquart) in tapereba fruits (Spondias mombin L.), with parasitism of 29.5\%. In guajava fruits (Psidium guajava L.) at Rio Branco County, only D. areolatus on $A$. obliqua occurred, with parasitism of $2.7 \%$.

KEYWORDS: Fruit flies, Parasitism, Tapereba, Guajava, Western Amazon

${ }_{1}$ Embrapa Florestas - Estrada da Ribeira, km 111 - C. Postal 319 CEP 83411-000 - Colombo - PR. e-mail: marcilio@cnpf.embrapa.br

2 Embrapa Acre - Rodovia BR 364, km 14 - C. Postal 321 CEP 69908-970 - Rio Branco - AC. E-mail: elizangela@cpafac.embrapa.br 
A fauna de parasitóides de moscas-das-frutas pertence principalmente à família Braconidae. Canal \& Zucchi (2000) relataram a ocorrência de 13 espécies de braconídeos parasitóides de Tephritidae no Brasil.

$\mathrm{Na}$ região amazônica brasileira são vários os relatos de distribuição e ocorrência de moscas-das-frutas e seus hospedeiros, no entanto, informaçôes sobre parasitismo ainda são escassas (Silva \& Ronchi-Teles, 2000).

Canal et al. (1995) coletaram, no estado do Amazonas, cinco espécies de parasitóides da família Braconidae obtidas de Anastrepha spp. Opius sp. foi a predominante, ocorrendo também Doryctobracon areolatus (Szépligeti), Opius bellus Gahan, Utetes anastrephae (Viereck) e Asobara anastrephae (Muesebeck).

Ohashi et al. (1997) encontraram O. bellus, D. areolatus e $U$. anastrephae $\mathrm{em}$ A. obliqua (Macquart) atacando frutos de acerola no Pará, sendo que o parasitismo não foi estimado. Os autores citam que os braconídeos encontrados são endoparasitóides solitários, que ovipositam no estágio larval das moscas-das-frutas e emergem do pupário do hospedeiro. Gomes-Silva et al. (1998), também na cultura da acerola no Pará, encontraram apenas $D$. areolatus em $A$. obliqua.

Silva \& Ronchi-Teles (2000) relataram que, em coletas de frutos de taperebá, A. obliqua foi parasitada por Opius sp., $O$. bellus e $A$. anastrephae, enquanto $A$. antunesi Lima sofreu parasitismo somente por Opius sp.

No Amapá, em diversas espécies de frutos, Carvalho \& Malavasi (2003) observaram seis espécies de parasitóides associados a $A$. striata Schiner, sendo cinco da família Braconidae (D. areolatus, Opius sp., A. anastrephae, $U$. anastrephae e Doryctobracon sp.) e a espécie Aganaspis pelleranoi (Brèthes) da família Figitidae, subfamília Eucoilinae. Silva \& Silva (2007), em diferentes espécies frutíferas, encontraram diversas espécies de moscas-das-frutas e de parasitóides, acrescentando $O$. bellus à lista de parasitóides presentes no Amapá.

No estado do Acre, Thomazini et al. (2003), em levantamento com frascos caça-moscas, relataram ocorrência de seis espécies do gênero Anastrepha, predominando $A$. obliqua $(98,8 \%)$. No entanto, não há relatos de parasitóides associados a tefritídeos no estado. A diversidade de hospedeiros que ocorre na região pode favorecer a presença de várias espécies de moscas-das-frutas e, consequentemente, de seus parasitóides. Desse modo, o objetivo deste trabalho foi determinar as espécies de parasitóides e os índices de parasitismo em moscas-das-frutas provenientes de frutos coletados em municípios do sudeste acreano.

Coletas esporádicas de frutos de goiaba (Psidium guajava L.) e taperebá (Spondias mombin L.), também conhecido como cajá, foram realizadas nos meses de fevereiro e março de
2004, no campo experimental da Embrapa Acre, município de Rio Branco, AC e na rodovia BR 364, km 05, município de Bujari, estado do Acre.

Os frutos foram levados para o Laboratório de Entomologia da Embrapa Acre, onde foram contados, pesados e acondicionados em bandejas plásticas com areia esterilizada e umedecida protegidas por tecido de organza. Diariamente a areia era peneirada, os pupários recolhidos e acondicionados em potes plásticos com areia umedecida. Os potes foram acondicionados em sala climatizada $\left(26 \pm 2^{\circ} \mathrm{C}, 60 \pm 10 \%\right.$ de umidade relativa e $12 \mathrm{~h}$ fotofase) e observados diariamente para verificar a emergência de moscas ou parasitóides e posterior identificação.

No município de Bujari foram coletados 271 frutos de taperebá $(2,4 \mathrm{~kg})$ diretamente no solo e 97 frutos de goiaba $(4,1 \mathrm{~kg})$ na planta. Dos frutos de taperebá foram obtidos 468 pupários, com índice de infestação de 1,7 pupários/ fruto e 195 pupários $/ \mathrm{kg}$ de fruto. Houve a emergência de 89 moscas (viabilidade pupal de 19,0\%), sendo 56 machos e 33 fêmeas (razão sexual de 62,9\%) somente de A. obliqua. Dos demais pupários emergiram 138 parasitóides pertencentes a três espécies: $O$. bellus $(72,5 \%), D$. areolatus $(26,8 \%)$ e $U$. anastrephae $(0,7 \%)$, apresentando um índice de parasitismo de $29,5 \%$. Quanto aos frutos de goiaba, emergiram apenas dois indivíduos de $A$. striata e um de $A$. obliqua e não houve emergência de parasitóides.

Canal et al. (1995) relataram, em frutos de taperebá no Amazonas, além das espécies de braconídeos encontradas no Acre, a presença de $A$. anastrephae e Opius sp. Segundo os autores, só não foi possível a associação parasitóide/A. obliqua com Opius sp., no entanto, Silva \& Ronchi-Teles (2000) observaram essa associação.

Silva \& Silva (2007) registraram parasitismo de 21,7\% em cinco espécies de moscas-das-frutas originárias de frutos de taperebá no Amapá. Também ocorreram D. areolatus (espécie mais abundante), $U$. anastrephae e $O$. bellus, além de Opius sp.

Segundo Canal \& Zucchi (2000) o parasitismo natural em moscas-das-frutas é muito variável, dependendo do local, época, mosca e fruto hospedeiro, no entanto, os índices encontrados na maioria dos trabalhos raramente ultrapassam $50 \%$.

No município de Rio Branco, foram coletados 122 frutos de goiaba na planta $(5,2 \mathrm{~kg})$, obtendo-se 147 pupários, com índice de infestação de 1,2 pupários/fruto e 28,3 pupários/ $\mathrm{kg}$ de fruto. A viabilidade pupal foi de 29,3\% (43 moscas), emergindo 12 machos e 31 fêmeas de $A$. obliqua (razão sexual de 27,9\%). Emergiram apenas quatro exemplares de D. areolatus, com índice de parasitismo de 2,7\%. Canal et al. 
(1995), em amostras de goiaba no Amazonas, obtiveram $D$. areolatus associado a $A$. striata.

Esse é o primeiro registro de parasitóides de moscasdas-frutas no estado do Acre, contudo, os braconídeos parasitóides de Anastrepha encontrados neste trabalho são de ocorrência comum no Brasil (Canal \& Zucchi, 2000) e estão distribuídos por grande parte da região Amazônica (Canal et al., 1995; Ohashi et al., 1997; Gomes-Silva et al., 1998; Silva e Ronchi-Teles, 2000; Carvalho \& Malavasi, 2003; Silva \& Silva, 2007).

\section{AGRADECIMENTOS}

Ao Dr. Miguel Francisco de Souza Filho, pesquisador do Centro Experimental Central do Instituto Biológico - APTA, em Campinas, SP, pela identificação dos parasitóides.

\section{BIBLIOGRAFIA CITADA}

Canal, N.A.; Zucchi, R.A. 2000. Parasitóides - Braconidae. In: Malavasi, A.; Zucchi, R.A. (Eds.). Moscas-das-frutas de importância econômica no Brasil. Conhecimento básico e aplicado. Holos, Ribeirão Preto, São Paulo. p. 119-126.

Canal, N.A.D.; Zucchi, R.A.; Silva, N.M.; Silveira-Neto, S. 1995. Análise faunística dos parasitóides (Hymenoptera, Braconidae) de Anastrepha spp. (Diptera, Tephritidae) em Manaus e Iranduba, Estado do Amazonas. Acta Amazonica, 25(3/4): 235-246.
Carvalho, R.S.; Malavasi, A. 2003. Monitoramento de parasitóides nativos de moscas-das-frutas (Tephritidae) antes da liberação de Diachasmimorpha longicaudata na região Amazônica. Embrapa Mandioca e Fruticultura, Cruz das Almas, Bahia. Comunicado Técnico, 96. 8pp.

Gomes-Silva, J.; Uramoto, K.; Malavasi, A. 1998. First report of Ceratitis capitata (Diptera: Tephritidae) in the Eastern Amazon, Para, Brazil. Fla. Entomol., 81(4): 574-577.

Ohashi, O.S.; Dohara, R.; Zucchi, R.A.; Canal-D, N.A. 1997. Ocorrência de Anastrepha obliqua (Macquart) (Diptera: Tephritidae) em acerola Malpighia punicifolia L. no estado do Pará. An. Soc. Entomol. Brasil, 26(2): 389-390.

Silva, N.M.; Ronchi-Teles, B. 2000. Amapá, Amazonas, Pará, Rondônia e Roraima. In: Malavasi, A.; Zucchi, R.A. (Eds.). Moscas-das-frutas de importancia econômica no Brasil. Conhecimento básico e aplicado. Holos, Ribeirão Preto, São Paulo. p. 203-209.

Silva, W.R.; Silva, R.A. 2007. Levantamento de moscas-das-frutas e de seus parasitóides no município de Ferreira Gomes, Estado do Amapá. Ciênc. Rur., 37(1): 265-268.

Thomazini, M.J.; Albuquerque, E.S.; Souza Filho, M.F. 2003. Primeiro registro de espécies de Anastrepha (Diptera: Tephritidae) no estado do Acre. Neotrop. Entomol., 32(4): 723-724.

Recebido em 16/05/2007

Aceito em 03/06/2008 
